\title{
Patients with HFpEF and HFrEF have different clinical characteristics but similar prognosis: a retrospective cohort study
}

\author{
Tamrat Befekadu Abebe*, Eyob Alemayehu Gebreyohannes, Yonas Getaye Tefera and Tadesse Melaku Abegaz
}

\begin{abstract}
Background: Globally, heart failure (HF) has been recognized as one of the major cardiovascular disorder with high morbidity, mortality and considerable social impact. In Sub Saharan African countries, HF has turned out as a leading form of cardiovascular diseases, and has considerable socioeconomic impact. However, there are differences in clinical characteristics and survival status among patients with preserved (HFpEF) and reduced (HFrEF) ejection fraction. The aim of this study is to outline the clinical characteristics and medication profile, assess the survival status and prognostic factors of Ethiopian HF patients with HFrEF and HFpEF.

Methods: A retrospective cohort study was carried out and we employed medical records of patient's, admitted as a result of HF to the University of Gondar Referral Hospital in the period between December 02, 2010 and December 01, 2015 due to HF. Kaplan Meier curve was used to analyze the survival status and log rank test was used to compare the curves. Cox regression was used to analyze independent predictors of mortality in all HF patients.

Results: Of the 850 patients who were admitted due to HF, 311 patients met the inclusion criteria. Majority of the patients had HFpEF (52.73\%) and tend to be women (76.22\%). They predominantly had etiologies of valvular and hypertensive heart diseases, and took calcium channel blockers and anticoagulants. Conversely, patients with HFrEF had etiologies of ischemic heart disease and dilated cardiomyopathy and were prescribed angiotensine converting inhibitors (ACEI) and beta blockers. Kaplan Meier curves and Log rank test $(p=0.807)$ showed that there was no statistically significant difference in the mortality difference among patients with HFpEF and HFrEF. On the other hand, Cox regression analysis showed advanced age, lower sodium level, higher creatinine level and absence of medications like ACEI, spironolactone and statins independently predicted mortality in all HF patients.
\end{abstract}

Conclusions: Different clinical characteristics were found in both groups of HF patients. There was no difference in survival outcome between patients with HFrEF and HFpEF.

Keywords: Heart failure, Ejection fraction, Clinical characteristics, Survival, Ethiopia

\section{Background}

Heart failure (HF) is one of the major cardiovascular disorder with high morbidity and mortality and rising costs, which account for $1-2 \%$ of the annual health budget of most developed nations [1, 2]. HF primarily involves (affects) people with advanced age, and incidence and prevalence increases progressively in those age $>60$ years [3]. The most frequent prevalence estimate for the adult population at large is $2 \%$ and more

\footnotetext{
* Correspondence: Befekadutamrat@gmail.com

Department of Clinical Pharmacy, School of Pharmacy, College of Medicine and Health Science, University of Gondar, Gondar, Ethiopia
}

than $10 \%$ particularly in those aged 75 years and older [2, 4-6]. In Sub Saharan African countries (SSA), HF has turned out as a leading form of cardiovascular disease, and has considerable socioeconomic impact owing to its high prevalence, mortality and impact on young generations [7]. Unlike developed nations, the most prevailing causes of HF in Africans remains largely non ischemic [7]. Two third of HF cases in SSA are mainly secondary to Hypertension (HTN), cardiomyopathy and rheumatic heart disease $[7,8]$. In contrast, in industrialized nations, coronary

(c) The Author(s). 2016 Open Access This article is distributed under the terms of the Creative Commons Attribution 4.0 International License (http://creativecommons.org/licenses/by/4.0/), which permits unrestricted use, distribution, and reproduction in any medium, provided you give appropriate credit to the original author(s) and the source, provide a link to the Creative Commons license, and indicate if changes were made. The Creative Commons Public Domain Dedication waiver (http://creativecommons.org/publicdomain/zero/1.0/) applies to the data made available in this article, unless otherwise stated. 
artery disease, either alone or in combination with HTN, is the prominent cause of HF $[9,10]$.

Left ventricular dysfunction (LVD) is categorized into systolic and diastolic dysfunction. A LVEF above 50\% and below 40 are considered reserved and reduced ejection fractions, respectively, leaving an intermediary range of 40 to $50 \%$ [11]. Irregularity in the filling properties or capacity of the left ventricle in patients with LVEF $>50$ is used to classify diastolic dysfunction [11, 12]. HF is usually considered typical when presenting in patients with dilated hearts and systolic dysfunction (ejection fraction $(\mathrm{EF})<40 \%)$. As a result, the most therapeutic evidence, including effective pharmacological and device therapies that have led to impressive improvements in survival is in this group of patients with HFrEF. By contrast, most clinical trials excluded patients with HF with preserved ejection fraction (HFpEF > 50\%) [11, 12].

In the past three decades, prevalence of $\mathrm{HF}$ is on the rise. [3, 13, 14]. Demographically, prevalence of HF has certain difference between patients with systolic dysfunction (SDf) and diastolic dysfunction (DDf). Most patients with DDf are usually older age and female, and have left ventricular hypertrophy and arterial hypertension [15-18]. Moreover, there are disparities on the prognosis of patients with SDf and DDf as some researches demonstrated that morbidity and mortality is worse in the earlier group while other studies emphasize that there is no convincing discrepancy in prognosis between these groups [13, 19-22]. To the best of our knowledge, unlike western countries, we did not found sufficient studies on the clinical characteristics of patients with $\mathrm{HF}$ with reduced ejection fraction (HFrEF) and HFpEF in SSA countries. Hence, we aimed to evaluate HF patient's clinical characteristics and outcome, and medication profile based on patients recorded EF during admission to Gondar University Referral Hospital (GURH), Ethiopia.

\section{Methods}

\section{Study population}

We retrospectively assessed medical transcript of patients who had been admitted with a diagnosis of HF in Internal Medicine ward of GURH in the period between December 02, 2010 and December 01, 2015. Patients who had been diagnosed HF, are 18 years of age or older, and with presence of two or more of the adapted Framingham criteria or presence of one major criteria and two minor criteria has been included in the study. Major criteria include: presence of sign and symptoms of raised jugular venous pressure, paroxysmal nocturnal dyspnea, clinical cardiomegaly confirmed by chest X- ray, basal crepitation, third heart sound, pulmonary edema confirmed by chest X- Ray, hepatojugular reflux and acute pulmonary edema. Minor criteria include: heart rate $>120$ beats per minute, orthopnea, exertional dyspnea, nocturnal cough, hepatomegaly, pleural effusion, and peripheral edema. Exclusion criteria were patients who had concomitant infection in addition to HF, patients who did not have echocardiography record, patients who were New York Heart Association (NYHA) Class I and class II during admission and patients who did not have laboratory analysis records on complete blood count, electrolytes and creatinine level. The internal medicine ward received around 850 patients during the study period and 539 were excluded from the study based on the exclusion criteria.

Patients were grouped based on their LVEF record into two: patients with HFpEF (LVEF $\geq 50 \%$ ) and patients with HFrEF (LVEF < 50\%). Ejection fraction of the participants were measured using echocardiogram during their first admission to the internal medicine ward by a radiologist. Survival status of the patients were recorded based on their vital status record on last hospital discharge from internal medicine ward or the last time patient's came for routine checkup or to refilled their medication. Patient's data was collected by two clinical pharmacists (co - authors) during the study period.

Hypertension was determined as blood pressure 140/ $90 \mathrm{mmHg}$ or more, anemia as hemoglobin level $<13 \mathrm{~g} /$ $\mathrm{dl}$ for men and $<12 \mathrm{~g} / \mathrm{dl}$ for women.

The etiology of HF was determined based on the following algorism: Ischemic, when the patient was diagnosed with Ischemic heart disease (IHD); Valvular, when there was moderate valulopathy with no IHD; hypertensive, when there was previous history of hypertension but no evidence of additional cardiovascular disease; dilated cardiomyopathy (DCMP), when there was no other known cardiac cause and had LVEF $<50 \%$; and Cor pulmonale, when right sided heart failure without left ventricular dysfunction is present.

\section{Statistics}

Statistical analysis was conducted for both quantitative and qualitative variables. Group variables were indicated in percentage and Chi square test was used. A probability of type I error $<5 \%$ was considered significant. Continuous variables were revealed in mean $\pm \mathrm{SD}$ and independent $\mathrm{t}$ - test was used with a probability of type I error $<5 \%$ considered significant. Kaplan - Meier survival curves were designed and analyzed with the Mantel log rank test to measure the significance. Univariate Cox regression analysis was used to determine the co-factors with momentous outcome on allcause mortality. Multivariate Cox regression analysis was implemented to determine the independent foreboding factors for all-cause death. All data were analyzed with SPSS version 20.0 (SPSS Inc. Chicago, IL) software for windows.

\section{Results}

Of 850 patients who were admitted to GURH due to HF, in the period between December 02, 2010 and December 
01, 2015, 311 patients met the inclusion criteria. From the study group, 164 patients had HFpEF ( $E F \geq 50 \%)$ and the remaining participants (147) had HFrEF (EF < $50 \%)$. Table 1 shows baseline clinical characteristics of the two groups. The mean age of the participants were $53.58( \pm 16.902)$ years with no significant divergence among the groups $(54.20( \pm 16.587)$ Vs.52.88 ( \pm 17.246$)$, $P=0.496)$, and women accounted for the majority of patients with $\mathrm{LVEF} \geq 50$ (76.22\% vs. $62.59 \%, P=0.009$ ). Analysis of cardiovascular risk factors such as hypertension and diabetes, other co morbidities like anemia, atrial fibrillation, and NYHA functional class revealed no compelling variance among the groups. However, heart failure etiology clearly distinguished between the HFrEF and HFpEF groups. In the earlier groups Ischemic heart disease (IHD) $(21.09 \%$ vs. $10.98 \%, P=0.015)$ and DCMP $(21.77 \%$ vs. $4.27 \%, P=<0.001)$ were more prevalent; whereas, VHD (34.01\% vs. $45.96 \%, P=0.020)$ and HHD $(11.56 \%$ vs. $20.12 \%, P=0.040)$ were more prevalent in the later groups. There were also significant differences between patients with HFpEF and HFrEF in their heart rate $(95.60( \pm 21.177)$ Vs.89.93 ( \pm 16.287$), P=0.009$ ).

\section{Medical treatment}

Table 2 compares treatments at discharge in patients in the two groups. There were no significant difference in the prescription of diuretics, spironolactone, antiplatelet agents, digoxin and statins. Patients classified as having depressed LVEF were usually prescribed angiotensin converting enzyme inhibitor (ACEI) and beta blockers. On the other hand, anti-coagulants and calcium channel blockers were more frequently prescribed in patients with HFpEF.

\section{Results of laboratory analyses and echocardiograms}

Higher hemoglobin levels were measured in patients with reduced ejection fraction than preserved ejection fraction $(13.31 \pm 3.76$ vs. $12.47 \pm 3.08, P=0.031)$. Greater ventricular dimension were recorded in patients with HFrEF $(57.38 \pm 9.07$ vs. $46.10 \pm 8.64, \mathrm{P}=<0.001)$. The mean EF in patients with preserved and reduced EF were $62.57 \pm 8.62$ and $40.36 \pm 6.81$ respectively (Table 3 ).

\section{Survival analysis}

The mean duration of follow up was $24.56 \pm 17.79$ months. Mortality were $14.02 \%$ in patients with $\operatorname{HFpEF}$ (23 patients) and $14.29 \%$ in patients with HFrEF (21 patients). Kaplan Meier survival curves (Fig. 1) shows there were no significant difference in survival status of patients with HFrEF and HFpEF (Log Rank test, $P=0.807$ ). On the other hand, univariate Cox regression analysis showed that age, sodium level, creatinine level, IHD, Spironolactone, and digoxin were significantly associated with morality in patients with HF (Table 4). Multivariate Cox regression analysis, including the significant predictors of mortality

Table 1 Clinical characteristics of Heart Failure patients based on Preserved of reduced ejection fraction

\begin{tabular}{|c|c|c|c|c|}
\hline Variable & Total patients $(n=311)$ & LVEF $\geq 50 \%(n=164)$ & LVEF < 50\% $(n=147)$ & $P$ value \\
\hline Women, n (\%) & $217(69.77)$ & $125(76.22)$ & $92(62.59)$ & 0.009 \\
\hline Age, Years (mean \pm SD) & $53.58( \pm 16.902)$ & $54.20( \pm 16.587)$ & $52.88( \pm 17.246)$ & 0.496 \\
\hline Anemia, n (\%) & $118(37.94)$ & $65(39.63)$ & $53(36.05)$ & 0.516 \\
\hline$A F, n(\%)$ & $79(25.41)$ & $47(28.66)$ & $32(21.77)$ & 0.163 \\
\hline DM, n (\%) & $4(1.29)$ & $2(1.22)$ & $2(1.36)$ & 0.912 \\
\hline Hypertension, n (\%) & $97(0.312)$ & $56(34.15)$ & $41(27.89)$ & 0.235 \\
\hline Heart Rate ( mean \pm SD) & $92.88( \pm 19.166)$ & $95.60( \pm 21.177)$ & $89.93( \pm 16.287)$ & 0.009 \\
\hline Systolic BP & $122.75( \pm 24.231)$ & $125.06( \pm 26.911)$ & $120.18( \pm 20.651)$ & 0.072 \\
\hline NYHA Functional Class & & & & 0.274 \\
\hline Class III, n (\%) & $82(26.37)$ & $39(23.78)$ & $43(29.25)$ & \\
\hline Class IV, n (\%) & $229(73.63)$ & $125(76.22)$ & $104(70.75)$ & \\
\hline \multicolumn{5}{|l|}{ Etiology } \\
\hline IHD, n (\%) & $49(15.76)$ & $18(10.98)$ & $31(21.09)$ & 0.015 \\
\hline HHD, n (\%) & $50(16.08)$ & $33(20.12)$ & $17(11.56)$ & 0.040 \\
\hline VHD, n (\%) & $127(40.84)$ & $77(46.95)$ & $50(34.01)$ & 0.020 \\
\hline DCMP, n (\%) & $39(12.54)$ & $7(4.27)$ & $32(21.77)$ & $<0.001$ \\
\hline Cor pulmonale, n (\%) & $14(4.50)$ & $9(5.48)$ & $5(3.40)$ & 0.376 \\
\hline Others, n (\%) & 32 (10.29) & $20(12.20)$ & $12(8.16)$ & 0.243 \\
\hline
\end{tabular}

$A F$ atrial fibrillation, $B P$ blood pressure, $D C M P$ dilated cardiomyopathy $D M$ diabetes mellitus, $H H D$ hypertensive heart disease, IHD ischemic heart disease, $N Y H A$ New York Heart Association, SD standard deviation 
Table 2 Medication profile of heart failure patients based on ejection fraction

\begin{tabular}{llll}
\hline Medication & LVEF $\geq 50(n, 164)$ & LVEF < 50\% $(n, 147)$ & $P$ value \\
\hline ACEI n, \% & $34(15.85)$ & $80(40.82)$ & $<0.001$ \\
Beta Blocker n, \% & $45(21.95)$ & $73(36.73)$ & $<0.001$ \\
Diuretics n, \% & $146(74.39)$ & $136(70.75)$ & 0.290 \\
Spironolactone n, \% & $114(57.93)$ & $95(48.99)$ & 0.359 \\
Digoxin n, \% & $46(23.17)$ & $33(17.69)$ & 0.257 \\
Statin n, \% & $24(11.59)$ & $30(13.61)$ & 0.180 \\
Anticoagulants n, \% & $33(17.07)$ & $12(14.70)$ & 0.003 \\
Antiplatelet agents n, \% & $33(15.24)$ & $39(17.69)$ & 0.181 \\
CCB n, \% & $21(9.76)$ & $7(4.76)$ & 0.013 \\
\hline
\end{tabular}

$A C E l$ angiotensin converting enzyme inhibitor, $C C B$ calcium channel blocker

identified on univariate Cox regression, showed that advanced age, low sodium level, high creatinine level, and absences of medications (spironolactone, ACEI and satin) significantly predicted morality (Table 4).

\section{Discussion}

The present research analyzed data from a retrospective observational cohort of HF patients to assess clinical characteristics, medication profile and determinants of mortality among HF patients with HFrEF and HFpEF who were admitted at GURH.

The prevalence of HFpEF is on the raise with period in developed nations $[13,23]$, varies depending on the age of the patient, race and the cutoff values for LVEF. In spite of that, there is a pervasive agreement that HFpEF is prominent in more than a third of all patients admitted with HF [19, 24-27]. In our study, the prevalence of HFpEF was $52.73 \%$ which was in alignment with other studies [28-30]. A recent study conducted by L. Martínez-Bra na et al. found that prevalence of HFpEF in Spain was $72.2 \%$ [20]. A study carried out in Japan by $\mathrm{H}$. Kaneko et al. reported that prevalence of HFpEF was $72 \%$ [31]. In the Identification of Patients With Heart Failure and PREserved Systolic Function: an epidemiological regionalstudy (I PREFER) prevalence of HFpEF was about 65\% [32]. The disparity between these findings and our study might be credited to sample size variation of the study population, age of the patients, race and cutoff values for LVEF during the study.

Patients with HFpEF are at advanced age, women and more often have hypertension compared to patients with HFrEF [20, 25, 27, 31]. In a systematic review reported by E. E.S. van Riet et al., HFpEF was more prevalent with age $>60$ years and female gender [1]. In a meta-analysis study, compared with patients with HFrEF, those with HFpEF were older and more often women, and have a history of hypertension [10]. The differences in patients' backgrounds in our study were almost indistinguishable to those of previous articles as patients with HFpEF in this study were older and more often female.

Regarding the etiology of HF, hypertensive heart disease (HHD) and VHD are more common in patients with HFpEF. Whereas, in patients with HFrEF, the most prevalent causes were IHD and DCMP [19, 20, 24, 26]. A meta-analysis conducted by R.N. Doughty et.al reported that, compared with the HFrEF patients, those with HFpEF more often had a history of Hypertension and less likely had IHD [10]. In I PREFER, Irbesartan clinical trial and the Effects of Candesartan for the Management of Patients With Chronic Heart Failure (CHARM) program, it were reported that HHD was the most important etiologic factor for the diagnosis of HFpEF and CAD is the leading cause for patients with HFrEF [32-34]. Similar finding were documented in our study, where IHD and DCMP were the leading etiologies for the prevalence of HFrEF; in contrast, VHD and HHD were responsible for the diagnosis of HFpEF. One of the interesting finding in our study was, the impact of IHD as an etiology of HF in patients with reduced ejection fraction. According to prior literatures, most of the etiologies in African population were non ischemic [7]. This disparity might indicate that the progressive change in the epidemiological pattern of the disease through time and the modification of individuals' life style.

In terms of drug treatment, ACEI, Beta - Blockers and Digitalis are mostly prescribed to patients with HFrEF $[19,26,31,35-37]$. However, CCB are usually indicated for patients with HFpEF [38]. This is further supported

Table 3 Laboratory and echocardiography results of heart failure patients based on ejection fraction

\begin{tabular}{lccc}
\hline Variable & LVEF $\geq 50(n, 164)$ & LVEF $<50 \%(n, 147)$ & $P$ value \\
\hline Hgb (Mean \pm SD) & $12.47 \pm 3.08$ & $13.31 \pm 3.76$ & 0.031 \\
Cr. (Mean \pm SD) & $1.1086 \pm 0.774$ & $1.0690 \pm 0.536$ & 0.598 \\
Sodium (Mean \pm SD) & $134.86 \pm 5.44$ & $135.31 \pm 7.92$ & 0.563 \\
LVEDD in mm (Mean \pm SD) & $46.10 \pm 8.64$ & $57.38 \pm 9.07$ & $<0.001$ \\
LVEF\% (mean \pm SD) & $62.57 \pm 8.62$ & $40.36 \pm 6.81$ & $<0.001$ \\
\hline
\end{tabular}

$\mathrm{Hgb}$ hemoglobin, $\mathrm{Cr}$ creatinine, LVEDD left ventricular end diastolic diameter, LVEF left ventricular ejection fraction, SD standard deviation 
Survival Functions

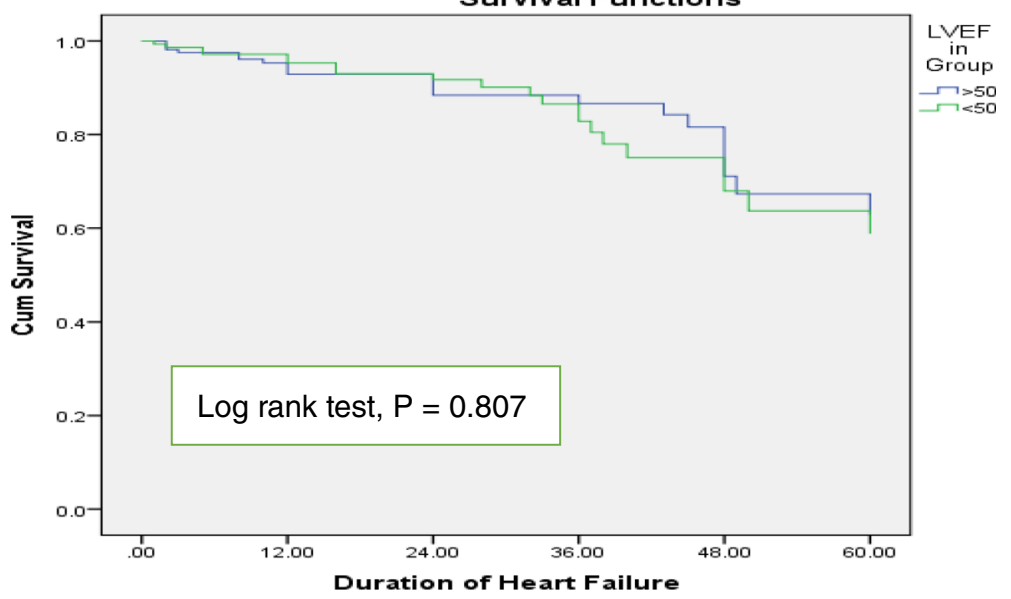

Fig. 1 Kaplan Meier survival curves at 60 months for patients with preserved and reduced ejection fraction

Table 4 Predictors of mortality to all causes of heart failure

\begin{tabular}{|c|c|c|c|c|}
\hline \multicolumn{3}{|l|}{ Univariate analysis } & \multicolumn{2}{|l|}{ Multivariate analysis } \\
\hline Variables & & Hazard ratio $(95 \% \mathrm{Cl})$ & Hazard ratio $(95 \% \mathrm{Cl})$ & $P$ value \\
\hline Gender & Male & $0.984(0.521-1.857)$ & $1.132(0.463-2.766)$ & 0.785 \\
\hline Age, Years & Age, years & $1.046(1.025-1.068)$ & $1.045(1.016-1.076)$ & 0.002 \\
\hline NYHA Class & Class IV & 1.549 (0.719-3.337) & $1.267(0.527-3.046)$ & 0.597 \\
\hline Anemia & Yes & $1.483(0.818-2.689)$ & $0.708(0.333-1.504)$ & 0.369 \\
\hline Sodium, mEq/L & & $0.933(0.896-0.972)$ & $0.913(0.851-0.980)$ & 0.011 \\
\hline Creatinine, mg/dl & & $2.602(2.052-3.300)$ & 1.966 (1.369-2.824) & $<0.001$ \\
\hline AF & Yes & $0.486(0.225-1.051)$ & $0.617(0.171-2.224)$ & 0.461 \\
\hline VHD & Yes & $0.636(0.342-1.185)$ & $1.420(0.413-4.886)$ & 0.578 \\
\hline $\mathrm{IHD}$ & Yes & $2.355(1.182-4.691)$ & $2.211(0.397-12.331)$ & 0.365 \\
\hline DCMP & Yes & $0.898(0.352-2.290)$ & $1.068(0.240-4.743)$ & 0.931 \\
\hline $\mathrm{HHD}$ & Yes & $1.036(0.481-2.229)$ & $1.272(0.338-4.794)$ & 0.722 \\
\hline LVEF & & $0.997(0.975-1.020)$ & $0.992(0.958-1.027)$ & 0.634 \\
\hline Diuritics & Yes & $0.877(0.269-2.858)$ & $0.690(0.180-2.650)$ & 0.589 \\
\hline Spironolactone & Yes & $0.388(0.214-0.703)$ & $0.343(0.158-0.743)$ & 0.007 \\
\hline ACEI & Yes & $0.952(0.510-1.778)$ & $0.258(0.098-0.680)$ & 0.006 \\
\hline Beta Blocker & Yes & $1.205(0.659-2.204)$ & $1.713(0.766-3.832)$ & 0.190 \\
\hline Digoxin & Yes & $0.313(0.132-0.746)$ & $0.407(0.095-1.736)$ & 0.224 \\
\hline Antiplatelates & Yes & $0.883(0.435-1.793)$ & $1.383(0.352-5.436)$ & 0.643 \\
\hline Anticoagulants & Yes & $1.700(0.817-3.541)$ & $2.429(0.845-6.978)$ & 0.099 \\
\hline Statin & Yes & $1.520(0.768-3.010)$ & $0.189(0.037-0.972)$ & 0.046 \\
\hline $\mathrm{CCB}$ & Yes & $1.555(0.720-3.359)$ & $0.815(0.287-2.317)$ & 0.701 \\
\hline
\end{tabular}

$A C E$ angiotensin converting enzyme inhibitor, $A F$ atrial fibrillation, $C C B$ calcium channel blocker, $D C M P$ dilated cardiomyopathy, $H H D$ hypertensive heart disease, $I H D$ ischemic heart disease, $L V E F$ left ventricular ejection fraction, NYHA New York Heart Association, VHD valvular heart disease

Factors included in multivariate Cox model include: Gender, Age, NYHA Class, presence of comorbidities such as anemia and AF, Common etiologies of HF such as VHD, IHD,HHD, and DCMP, Use of medications such as Diuretics, Spironolactone, ACEl, Beta Blocker, Digoxin, Antiplatelates, Anticoagulants, Statin and CCB, and laboratory values such as sodium and creatinine 
by 2016 ESC European heart failure guideline, as indicated amlodipine in HF patients with preserved ejection fraction and ventricular rhythm problem [39]. Unlike HF with HFrEF, patients with HFpEF did not benefit from the novel medications indicated to manage the disease and improve morbidity and mortality. Hence, there are few clinical trials on this group of patients and trials already conducted on ACEI/Angiotensin Receptor Blockers showed that there is no promising influence on reducing the mortality rate in patients with HFpEF [33, 40]. The CHARM Program study showed no significant effect on mortality, but showed significant benefit in preventing HF hospitalization [34]. One of the proposed predictions by Y. Juillière et al. was systemic hypertension is more frequently associated with preserved ejection fraction, resulting a higher rate of prescription of CCB. In contrast most of the etiologies in patients with HFrEF are usually IHD [38]. Similar findings were presented in our study, where most of patients with HFpEF took CCB and anticoagulants since hypertension and $\mathrm{AF}$ were more prevalent in this group of patients. However, ACEI and Beta blockers were more recommended in patients with HFrEF.

There is no clear cut variation in the long term clinical outcomes of patients with HFpEF and HFrEF. Studies conducted by Owan TE et al., F.P. Brouwers et al. and H. Kaneko et al. reported that patient with HFpEF had better prognosis than those with $\operatorname{HFrEF}[13,31,41]$. Nonetheless, no significant variation in mortality between patients with preserved and reduced LVEF were reported by other studies $[19,20,26]$. In the current study, there was no substantial difference (Log rank test, $P=0.807$ ) in the survival status of patients with preserved and reduced ejection fraction. However, patients with HFpEF had a relatively better survival status.

In the current study, multivariate cox regression analysis exhibited that the independent prognosticators of all causes of death in patients with HF were advanced age, low sodium level, high creatinine level, and absence of medications like statins, ACEI, and Spironolactone. Our findings were consistent with various studies; in a prospective study conducted by Macín SM, et al. [19] and Ojeda S, et al. [26] in Spain and a retrospective study in USA by Owan TE et al. [13] reported that advanced age, lower level of sodium, higher serum creatinine level as a predictor of unfavorable outcome in $\mathrm{HF}$ patients. In a retrospective study done by $\mathrm{H}$. Kaneko et al. [31] found that absence of statins in patients with HFrEF medication prescription as a prognosticator of mortality. In a randomized control trial conducted by Pitt B et al. [42], it was reported that aldosterone blockers had a momentous importance in lowering morbidity and mortality by decreasing atrial natriuretic peptide concentrations. The study of left ventricular dysfunction (SOLVD) determined that addition of ACEI in HF treatment had significantly decreased mortality and morbidity in patients with $\mathrm{HFrEF}$ [43].

\section{Study limitation}

Our study had several limitations. First, this study was carried out in a single center so the outcomes of the research cannot be generalized to all medical centers. Second, the sample size of the study population may not be sufficient enough to detect statistically significant differences. Third, the definition of HFrEF and HFpEF in the current study was based on LVEF, and it therefore remains not certain whether the study participants had objective documentation of diastolic dysfunction, as characterized by guiding principle for the diagnosis of HFpEF.

Despite these limitations, we believe that our study provides vital information on the clinical features and prognosis of patients with HF. Moreover, it will give a blue print for further clinical research in the area.

\section{Conclusions}

In the current study, majority of the patients presented with HFpEF. As in other studies, women, hypertensive and VHD etiologies were more predominant in patients with HFpEF and takes CCB and anticoagulants. Patients with HFrEF had IHD and DCMP etiologies. They usually took Beta blockers and ACEI. There was no compelling disparity in mortality between patients with HFrEF and HFpEF. However, older age, lower sodium level, higher creatinine level and absence of medications like ACEI, spironolactone and statins independently predicted mortality in all HF patients. These outcomes indicated that further research should be conducted and several factors should be considered for preserved or reduced LVEF management.

\section{Abbreviations \\ ACEl: Angiotensin-converting enzyme inhibitor; AF: Atrial fibrillation; CAD: Coronary artery disease; CCB: Calcium Channel Blockers; CHARM: The Effects of Candesartan for the Management of Patients With Chronic Heart Failure; Cr: Creatinine; DCMP: Dilated cardiomyopathy; DDf: Diastolic dysfunction; DM: Diabetes mellitus; EF: Ejection fraction; GURH: Gondar University Referral Hospital; HF: Heart failure; HFpEF: Heart Failure with preserved Ejection Fraction; HFrEF: Heart Failure with reduced Ejection Fraction; Hgb: Hemoglobin; HHD: Hypertensive heart disease; \\ HTN: Hypertension; I PREFER: Identification of Patients With Heart Failure and PREserved Systolic Function: an epidemiological regional study; IHD: Ischemic heart disease; LVD: Left ventricular dysfunction; LVEDD: Left ventricular end diastolic dimension; LVEF: Left ventricular ejection fraction; NYHA: New York Heart Association; SD: Standard deviation; SDF: Systolic dysfunction; SOLVED: The study of left ventricular dysfunction; SSA: Sub Saharan Africa; VHD: Valvular heart disease}

\section{Acknowledgement}

We would like to acknowledge staffs from medical records departments for organizing and searching patient's medical charts. 


\section{Availability of data and materials}

The datasets during and/or analysed during the current study available from the corresponding author on reasonable request.

\section{Authors' contributions}

TBA and TMA supervised and conceived the study, prepared study protocol, interpret and analyzed data and wrote the draft of manuscript. YGT and EAG contributed to data collection, data entry and performed literature review. All the authors read and approved the final manuscript.

\section{Competing interests}

The authors declare that they have no competing interests.

\section{Consent for publication}

Not applicable.

\section{Ethics approval and consent to participate}

Ethical clearance was obtained to access patients medical records from GURH ethical board of School of Pharmacy. Since the data collection was conducted retrospectively from patient medical records, and patients were not directly involved in data collection, informed consent was not sought from patients.

\section{Received: 29 July 2016 Accepted: 16 November 2016}

\section{Published online: 21 November 2016}

\section{References}

1. van Riet EE, Hoes AW, Wagenaar KP, Limburg A, Landman MA, Rutten FH. Epidemiology of heart failure: the prevalence of heart failure and ventricular dysfunction in older adults over time. A systematic review. Eur J Heart Fail. 2016;18(3):242-52.

2. Sayago-Silva I, Garcia-Lopez F, Segovia-Cubero J. Epidemiology of heart failure in Spain over the last 20 years. Rev Esp Cardiol (English ed). 2013; 66(8):649-56.

3. Mosterd A, Hoes AW. Clinical epidemiology of heart failure. Heart. 2007; 93(9):1137-46

4. Anguita Sanchez M, Crespo Leiro MG, de Teresa GE, Jimenez Navarro M, Alonso-Pulpon L, Muniz GJ. Prevalence of heart failure in the Spanish general population aged over 45 years. The PRICE Study. Rev Esp Cardiol. 2008;61(10):1041-9.

5. Massie BM, Shah NB. Evolving trends in the epidemiologic factors of heart failure: rationale for preventive strategies and comprehensive disease management. Am Heart J. 1997;133(6):703-12.

6. McMurray JJ, Adamopoulos S, Anker SD, Auricchio A, Bohm M, Dickstein K, et al. ESC guidelines for the diagnosis and treatment of acute and chronic heart failure 2012: The Task Force for the Diagnosis and Treatment of Acute and Chronic Heart Failure 2012 of the European Society of Cardiology. Developed in collaboration with the Heart Failure Association (HFA) of the ESC. Eur J Heart Fail. 2012;14(8):803-69.

7. Ntusi NB, Mayosi BM. Epidemiology of heart failure in sub-Saharan Africa. Expert Rev Cardiovasc Ther. 2009; 7(2):169-80.

8. Parry EH. Diagnosis and management of heart failure in the young adult African. Br Med J. 1966;2(5522):1119-22.

9. McMurray JJ, Stewart S. Epidemiology, aetiology, and prognosis of heart failure. Heart. 2000;83(5):596-602.

10. Robert ND. The survival of patients with heart failure with preserved or reduced left ventricular ejection fraction: an individual patient data metaanalysis. Eur Heart J. 2012;33(14):1750-7.

11. Lam CS, Solomon SD. The middle child in heart failure: heart failure with mid-range ejection fraction (40-50\%). Eur J Heart Fail. 2014;16(10):1049-55.

12. Kindermann M. How to diagnose diastolic heart failure: a consensus statement on the diagnosis of heart failure with normal left ventricular ejection fraction by the Heart Failure and Echocardiography Associations of the European Society of Cardiology. Eur Heart J. 2007;28(21):2686. author reply -7.

13. Owan TE, Hodge DO, Herges RM, Jacobsen SJ, Roger VL, Redfield MM. Trends in prevalence and outcome of heart failure with preserved ejection fraction. N Engl J Med. 2006;355(3):251-9.

14. Abhayaratna WP, Marwick TH, Smith WT, Becker NG. Characteristics of left ventricular diastolic dysfunction in the community: an echocardiographic survey. Heart. 2006;92(9):1259-64.
15. Fischer M, Baessler A, Hense HW, Hengstenberg C, Muscholl M, Holmer S, et al. Prevalence of left ventricular diastolic dysfunction in the community. Results from a Doppler echocardiographic-based survey of a population sample. Eur Heart J. 2003;24(4):320-8.

16. Klapholz M, Maurer M, Lowe AM, Messineo F, Meisner JS, Mitchell J, et al. Hospitalization for heart failure in the presence of a normal left ventricular ejection fraction: results of the New York Heart Failure Registry. J Am Coll Cardiol. 2004;43(8):1432-8.

17. Yancy CW, Lopatin M, Stevenson LW, De Marco T, Fonarow GC. Clinical presentation, management, and in-hospital outcomes of patients admitted with acute decompensated heart failure with preserved systolic function: a report from the Acute Decompensated Heart Failure National Registry (ADHERE) Database. J Am Coll Cardiol. 2006;47(1):76-84.

18. Fonarow GC, Stough WG, Abraham WT, Albert NM, Gheorghiade M, Greenberg BH, et al. Characteristics, treatments, and outcomes of patients with preserved systolic function hospitalized for heart failure: a report from the OPTIMIZE-HF Registry. J Am Coll Cardiol. 2007;50(8):768-77.

19. Macin SM, Perna ER, Cimbaro Canella JP, Alvarenga P, Pantich R, Rios N, et al. Differences in clinical profile and outcome in patients with decompensated heart failure and systolic dysfunction or preserved systolic function. Rev Esp Cardiol. 2004;57(1):45-52.

20. Martinez-Brana L, Mateo-Mosquera L, Bermudez-Ramos M, Valcarcel Garcia Mde L, Fernandez Hernandez L, Hermida Ameijeiras A, et al. Clinical characteristics and prognosis of heart failure in elderly patients. Rev Port Cardiol. 2015;34(7-8):457-63.

21. Somaratne JB, Berry C, McMurray JJ, Poppe KK, Doughty RN, Whalley GA. The prognostic significance of heart failure with preserved left ventricular ejection fraction: a literature-based meta-analysis. Eur J Heart Fail. 2009; 11(9):855-62.

22. Bhatia RS, Tu JV, Lee DS, Austin PC, Fang J, Haouzi A, et al. Outcome of heart failure with preserved ejection fraction in a population-based study. $\mathrm{N}$ Engl J Med. 2006;355(3):260-9.

23. Roger VL, Weston SA, Redfield MM, Hellermann-Homan JP, Killian J, Yawn $\mathrm{BP}$, et al. Trends in heart failure incidence and survival in a communitybased population. JAMA. 2004;292(3):344-50.

24. Mori Y, Nishikawa Y, Kobayashi F, Hiramatsu K. Clinical status and outcome of Japanese heart failure patients with reduced or preserved ejection fraction treated with carvedilol. Int Heart J. 2013;54(1):15-22.

25. Ho JE, Gona P, Pencina MJ, Tu JV, Austin PC, Vasan RS, et al. Discriminating clinical features of heart failure with preserved vs. reduced ejection fraction in the community. Eur Heart J. 2012;33(14):1734-41.

26. Ojeda S, Anguita M, Munoz JF, Rodriguez MT, Mesa D, Franco M, et al. Clinical characteristics and medium-term prognosis of patients with heart failure and preserved systolic function. Do they differ in systolic dysfunction? Rev Esp Cardiol. 2003;56(11):1050-6.

27. Lee DS, Gona P, Vasan RS, Larson MG, Benjamin EJ, Wang TJ, et al. Relation of disease etiology and risk factors to heart failure with preserved or reduced ejection fraction: insights from the national heart, lung, and blood institute's Framingham heart study. Circulation. 2009;119(24):3070-7.

28. Dunlay SM, Weston SA, Redfield MM, Killian JM, Roger VL. Anemia and heart failure: a community study. Am J Med. 2008;121(8):726-32.

29. Punnoose LR, Givertz MM, Lewis EF, Pratibhu P, Stevenson LW, Desai AS. Heart failure with recovered ejection fraction: a distinct clinical entity. I Card Fail. 2011;17(7):527-32.

30. Elshaer F, Hassan W, Fawzy ME, Lockyer M, Kharabsheh S, Akhras N, et al. The prevalence, clinical characteristics, and prognosis of diastolic heart failure: a clinical study in elderly Saudi patients with up to 5 years follow-up. Congest Heart Fail (Greenwich, Conn). 2009;15(3):117-22.

31. Kaneko H, Suzuki S, Yajima J, Oikawa Y, Sagara K, Otsuka T, et al. Clinical characteristics and long-term clinical outcomes of Japanese heart failure patients with preserved versus reduced left ventricular ejection fraction: a prospective cohort of Shinken Database 2004-2011. J Cardiol. 2013;62(2):102-9.

32. Magana-Serrano JA, Almahmeed W, Gomez E, Al-Shamiri M, Adgar D, Sosner $\mathrm{P}$, et al. Prevalence of heart failure with preserved ejection fraction in Latin American, Middle Eastern, and North African Regions in the I PREFER study (Identification of Patients With Heart Failure and PREserved Systolic Function: an epidemiological regional study). Am J Cardiol. 2011;108(9): 1289-96.

33. Massie BM, Carson PE, McMurray JJ, Komajda M, McKelvie R, Zile MR, et al. Irbesartan in patients with heart failure and preserved ejection fraction. $\mathrm{N}$ Engl J Med. 2008;359(23):2456-67. 
34. Yusuf S, Pfeffer MA, Swedberg K, Granger CB, Held P, McMurray JJ, et al. Effects of candesartan in patients with chronic heart failure and preserved left-ventricular ejection fraction: the CHARM-Preserved Trial. Lancet (London, England). 2003;362(9386):777-81.

35. Edelmann F, Stahrenberg R, Gelbrich G, Durstewitz K, Angermann CE, Dungen $\mathrm{HD}$, et al. Contribution of comorbidities to functional impairment is higher in heart failure with preserved than with reduced ejection fraction. Clin Res Cardiol. 2011;100(9):755-64.

36. Ather S, Chan W, Bozkurt B, Aguilar D, Ramasubbu K, Zachariah AA, et al. Impact of noncardiac comorbidities on morbidity and mortality in a predominantly male population with heart failure and preserved versus reduced ejection fraction. J Am Coll Cardiol. 2012;59(11):998-1005.

37. Varela-Roman A, Gonzalez-Juanatey JR, Basante P, Trillo R, Garcia-Seara J, Martinez-Sande $J$, et al. Clinical characteristics and prognosis of hospitalised inpatients with heart failure and preserved or reduced left ventricular ejection fraction. Heart. 2002;88(3):249-54.

38. Juilliere $Y$, Suty-Selton C, Riant E, Darracq JP, Dellinger A, Labarre JP, et al. Prescription of cardiovascular drugs in the French ODIN cohort of heart failure patients according to age and type of chronic heart failure. Arch Cardiovasc Dis. 2014;107(1):21-32.

39. Ponikowski P, Voors AA, Anker SD, Bueno H, Cleland JG, Coats AJ, et al. 2016 ESC Guidelines for the diagnosis and treatment of acute and chronic heart failure. Eur Heart J. 2015;37(27):ehw128.

40. Kitzman DW, Hundley WG, Brubaker PH, Morgan TM, Moore JB, Stewart KP et al. A randomized double-blind trial of enalapril in older patients with heart failure and preserved ejection fraction: effects on exercise tolerance and arterial distensibility. Circ Heart Fail. 2010;3(4):477-85.

41. Brouwers FP, de Boer RA, van der Harst P, Voors AA, Gansevoort RT, Bakker SJ, et al. Incidence and epidemiology of new onset heart failure with preserved vs. reduced ejection fraction in a community-based cohort: 11-year follow-up of PREVEND. Eur Heart J. 2013;34(19):1424-31.

42. Pitt B, Zannad F, Remme WJ, Cody R, Castaigne A, Perez A, et al. The effect of spironolactone on morbidity and mortality in patients with severe heart failure. N Engl J Med. 1999;341(10):709-17.

43. The SOLVD Investigators. Effect of enalapril on survival in patients with reduced left ventricular ejection fractions and congestive heart failure. $\mathrm{N}$ Engl J Med. 1991;325(5):293-302.

\section{Submit your next manuscript to BioMed Central and we will help you at every step:}

- We accept pre-submission inquiries

- Our selector tool helps you to find the most relevant journal

- We provide round the clock customer support

- Convenient online submission

- Thorough peer review

- Inclusion in PubMed and all major indexing services

- Maximum visibility for your research

Submit your manuscript at www.biomedcentral.com/submit

) Biomed Central 